Jurnal Konstruksi Hukum | ISSN: XXXX | E-ISSN: XXXX Vol. 1, No. 1, September 2020 Hal. 26-31|Available online at https://www.ejournal.warmadewa.ac.id/index.php/jukonhum DOI: https://doi.org/10.22225/jkh.1.1.2161.26-31

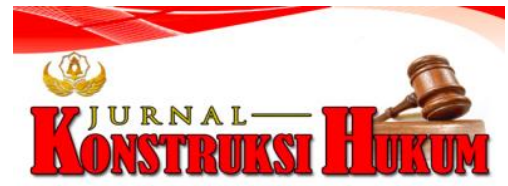

\title{
KEDUDUKAN WANITA BALI YANG DAHA TUA (TIDAK MENIKAH) TERHADAP HAK WARISAN DI DESA ADAT ABIANBASE KABUPATEN GIANYAR
}

\author{
Anak Agung Galuh Ratna Chyntia Dewi, I Wayan Wesna Astara, I Ketut Sukadana \\ Fakultas Hukum Universitas Warmadewa, Denpasar-Bali, Indonesia
}

\begin{abstract}
Abstrak
Wanita Bali yang tidak kawin masih tidak mempunyai perlindungan hukum dalam hak warisan. Hal ini karena masyarakat Hindu di Bali menganut sistem kekeluargaan patrilinial yang mana hanya anak laki-laki yang berhak menerima warisan. Dalam perkembangannya Majelis Utama Desa Pakraman Bali (MUDP) telah mengambil inisiatif memberikan hak warisan kepada wanita sebatas harta bersama orang tuanya. Dari latar belakang maka dirumuskan masalah sebagai berikut: (1) Bagaimana kedudukan Wanita Bali yang tidak menikah di Desa Adat Abianbase? (2) Bagaimana Implementasi Hak Waris Wanita Bali yang tidak menikah di Desa Adat Abianbase? Metode Penelitian yang digunakan yaitu menggunakan metode penelitian empiris-yuridis dengan meneliti kenyataan di Desa Adat Abianbase dan Keputusan Pasamuhan Agung III MUDP. Sumber data yang digunakan yaitu sumber data primer dan sumber data sekunder. Akhirnya disimpulkan bahwa kedudukan wanita yang tidak menikah sama dengan kedudukan wanita pada Hukum Adat Bali. Wanita yang tidak menikah tidak dapat memiliki hak warisan tetapi hanya berhak menikmati harta warisan orang tuanya sebagai biaya hidup bersama ahli waris lainnya. Implementasinya di Desa Adat Abianbase setelah adanya Keputusan Majelis Utama Desa Pakraman tentang hasil-hasil Pasamuhan Agung III MUDP Bali memerlukan waktu yang relatif lebih lama dikarenakan menyangkut tradisi yang sudah mendarah daging di kehidupan bermasyarakat.
\end{abstract}

Kata Kunci: Hukum adat waris; Kedudukan wanita; Wanita tidak kawin

\begin{abstract}
Balinese unmarried women still do not get legal protection in the rights of inheritance. This is because the Hindu community in Bali adheres to the Patrilinial family system that only men are entitled to receive inheritance. In the development of the main assembly of Pakraman village, Bali (MUDP) has taken the initiative to grant the rights of inheritance to women with their parents' property. From the fact, then the research problems are formulated as (1) How the position of unmarried Balinese women in the customary village of Abianbase? (2) How to implement the birthright of unmarried Bali women in the customary village of Abianbase. The research method used is empirical-juridical research implemented by researching the reality in Abianbase customary village and the Supreme Pasamuhan Decree of MUDP III. The data types used are the primary data and the secondary data. Finally it was concluded that the position of unmarried women equals the women's position on the customary law of Bali. The unmarried woman cannot have a birthright except the right to take advantages of their parents' inheritance as the cost of living with other heirs. The implementation is, in the traditional village Abianbase after the decree of the main assembly of Pakraman village about the results of Pasamuhan Agung III MUDP Bali, there' a need for a relatively longer time because it concerns the tradition that has been ingrained in society life.
\end{abstract}

Keywords: Inheritance law; Women's status; Unmarried woman

\section{PENDAHULUAN}

Dalam kamus Bahasa Bali daha tua berasal dari kata Daha yang berarti wanita remaja, wanita dewasa; dewasa, akil balig sedangkan Tua berarti sudah tua, (Kaler \& Sugriwa, 1978). Dalam tradisi yang ada di Bali, wanita mempunyai banyak peran penting untuk memelihara ajegnya budaya- budaya di Bali yang didasari oleh ajaran agama Hindu baik dalam lingkungan keluarga ataupun masyarakat. Wanita bisa dikatakan sebagai tulang punggung kegiatan agama yang jika tanpa peran wanita, kegiatan keagamaan tidak bisa dilakukan. Keberadaan wanita sesungguhnya tidak bisa diingkari dalam kehidupan bermasyarakat, dan harusnya hal tersebut bisa mengubah pola piker wanita ada pada nomor dua. 
Kekeluargaan dalam masyarakat adat Bali sering merasa khawatir dan bahkan ada yang menganggap sebagai suatu malapetaka apabila dalam sebuah keluarga tidak dapat memiliki keturunan laki-laki atau dalam keluarga tersebut hanya mempunyai keturunan wanita (Wibawa, 2006: 98). Pada masyarakat adat Bali yang menganut sistem perkawinan patrilineal anak wanita pada umumnya tidak berkedudukan sebagi penerus garis keturunan pada keluarga bapaknya, dimana wanita ini memiliki saudara laki-laki. Pada saat wanita ini kawin keluar, haknya terhadap warisan orang tuanya menjadi hilang, dimana harta orang tuanya selanjutnya akan di wariskan pada saudara laki-lakinya. Keadaan ini yang menjadi alasan mengapa anak laki-laki kemudian mengambil alih tanggung jawab untuk melaksankan kewajiban membayar utang orang tuanya pada saat meninggal nanti. Namun bagi anak laki-laki yang memiliki karakter penyayang tidak akan bersikap serakah dengan mengabaikan saudara wanitanya. Anak laki-laki ini dapat saja berbagi warisan orang tuanya dengan saudara wanitanya, apabila saudara laki-lakinya ini dapat secara iklas memberikannya apakah dengan bagian yang sama atau tidak. Anak wanita tetap mendapatkan hak warisan apabila tidak kawin keluar atau melakukan perkawinan dengan sistem nyentana dimana wanita berstatus purusa sedangkan suaminya berstatus pradana (Wibawa, 2006: 99).

Wanita dapat saja berstatus sebagai purusa apabila dilakukan perkawinan dengan sistem perkawinan nyentana, dimana suaminya yang berstatus sebagai pradana akan tinggal bersama dengan keluarga dari istrinya yang bersatus sebagai purusa. Pada kasus yang lain orang tua dapat saja memberikan sebagian hartanya kepada anak wanitanya yang kawin keluar sebagai bekal dalam mengarungi kehidupan berkeluarga. Harta ini dapat saja berupa mobil, sepeda motor, atau mungkin perhiasan. Harta yang dibawa oleh wanita yang kawin keluar inilah yang disebut sebagai harta bawaan (tetatadan).

Dewasa ini pewarisan pada masyarakat adat Bali telah mengalami perkembangan khususnya terhadap persamaan hak dalam pewarisan bagi wanita Bali yang telah diatur dalam Keputusan Majelis Utama Desa Pakraman Bali (MUDP) Bali No. 01/KEP/PSM-3/MDP Bali/X/2010, tanggal 15 oktober 2010, tentang Hasil-hasil Pasamuhan Agung III MUDP Bali, yang memutuskan hak dan kewajiban anak yang melangsungkan perkawinan terhadap harta warisan yang didalamnya terdiri atas harta pusaka dan harta gunakaya, hal lain yang diputuskan adalah bagaimana hak waris anak wanita baik itu anak kandung maupun anak angkat. Berikut ini dijelaskan singkat mengenai hak waris wanita menurut Keputusan Majelis Utama Desa Pakraman Bali (MUDP) Bali No.01/KEP/PSM- 3/MDP Bali/X/2010 pada bagian nomor 4 adalah sebagai berikut:

Mencermati berbagai fenomena mengenai ketimpangan daha tua dalam hak waris yang mana hak waris di Bali menggunakan sistem kekerabatan patrilinial. Sistem kekerabatan patrilinial ini sangat jelas menempatkan kaum laki- laki pada kedudukan yang lebih tinggi. Hal tersebutlah yang menyebabkan adanya diskriminasi gender antara anak laki-laki dan anak wanita dalam hukum adat di Bali. Kedudukan anak laki-laki di Bali yakni sebagai ahli waris, sebagai pelanjut nama keluarga, sebagai penerus keturunan, sebagai anggota masyarakat adat dan juga memiliki peran saat pengambilan keputusan keluarga ataupun masyarakat luas dan walaupun biasanya sudah memiliki anak wanita, cenderung masyarakat di Bali beranggapan merasa tidak mempunyai anak karena tidak mempunyai keterunan laki-laki. Hal tersebut dimana anak perempuan dipandang tidak akan bisa meneruskan purusa dan garis keturunan keluarga. Disamping itu minimnya sumber-sumber yang membahas wanita Bali yang daha tua yang mana sebagai wanita Bali yang tidak menikah mengenai kedudukan hak waris bagi mereka yang menjadi daha tua.

Realitas di lapangan menunjukkan bahwa perempuan yang merasa dirugikan dengan pembagian harta warisan yang dilakukan secara musyawarah, tidak banyak menuntut pembagian harta warisan dari harta bersama, karena takut lepas dari hubungan kekerabatan (Cahyowati, 2010). Dalam konteks perwakinan saja, terdapat hubungan horizontal bukan hubungan vertikal, sehingga tidak ada kondisi mendominasi dan didominasi. Semua pihak setara dan setara untuk bekerja sama dan mendapatkan hak yang sama (Harahap, 2013). Dalam konsep perwakinan pun, hak perempuan sebagai seorang istri terpenuhi secara hukum nasional dan hukum agama, seperti dalam agama Islam (Septhio, 2015; Saidah, 2017). Sedangkan dalam realita, agar seorang wanita dapat memperoleh hak dari harta orang menurut system pewarisan harta dalam agama Hindu, ada beberapa cara yang dapat ditempuh, seperti dengan memberikan sebagian harta warisan melalui pemberian atau bingkisan nikah yang disebut dengan dana jiwa, ajudan atau hadiah (Dangin dkk., 2015). Penelitian-penelitian sebelumnya hanya memfokuskan pada hak-hak wanita yang telah menikah, sedangkan hak seorang 
wanita yang hingga tua tidak menikah belum dimunculkan untuk mengungkap system pewarisan untuk memenuhi rasa keadilan bagi seluruh warga negara.

Berdasarkan latar belakang di atas, maka yang menjadi permasalahan adalah bagaimanakah kedudukan wanita Bali yang daha tua terhadap hak warisan di Desa Adat Abianbase Kabupaten Gianyar? bagaimanakah implementasi hak waris dari wanita yang daha tua di Desa Adat Abianbase Kabupaten Gianyar? Adapun tujuan khusus dalam penelitian ini, yaitu untuk mengetahui kedudukan wanita Bali yang daha tua terhadap hak warisan di Desa Abianbase Kabupaten Bali dan untuk mengetahui implementasi hak waris dari wanita Bali yang daha tua di Desa Abianbase Kabupaten Gianyar.

\section{METODE PENELITIAN}

Mengacu pada perumusan masalah, tipe penelitian yang digunakan dalam penelitian ini yaitu tipe penelitian empiris yaitu sebuah metode penelitian hukum yang berupaya untuk melihat hukum dalam artian yang nyata atau dapat dikatakan melihat, meneliti bagaimana bekerjanya hukum di masyarakat. Penelitian hukum Empiris terdiri dari penelitian terhadap identifikasi hukum dan penelitian terhadap efektivitas hukum (Efendi \& Ibrahim, 2018: 153).

Pendekatan masalah yang digunakan adalah bersifat empiris-yuridis, yaitu dengan cara meneliti kenyataan berupa awig-awig yang ada di desa tersebut dan Keputusan Pesamuhan Agung III MUDP Bali No. 01/Kep/PSM-3MDP Bali/X/2010, 15 Oktober 2010 kemudian mengaitkan dengan faktafakta yuridis yang selanjutnya menemukan pemecahan atas kesenjangankesenjangan.

Jenis sumber data yang dipergunakan dalam penelitian ini adalah berupa data primer dan data sekunder. Data primer merupakan sumber data yang diperoleh dari penelitian lapangan yang diperoleh langsung dari semua pihak yang terkait langsung di lapangan seperti keterangan tokoh masyarakat, prajuru adat dan hasil dari wawancara terhadap informan yang berada di Desa Adat Abianbase Kabupaten Gianyar. Data sekunder merupakan data yang di peroleh peneliti dari sumber yang sudah ada antara lain buku-buku penunjang, hasil-hasil karya ilmiah dari kalangan hukum dan data yang diperoleh dari Perpustakaan.

Dalam penelitian pengumpulan data primer dilakukan dengan cara observasi dan interview kepada informan yang dijadikan Dalam penelitian pengumpulan data primer dilakukan dengan cara observasi dan interview dari informan yang dijadikan. Data yang terkumpul selanjutnya dilakukan pengolahan dengan cara kuantitatif dan kualitatif serta dianalisis dengan cara deskritif analitis untuk mendapatkan bahwa hukum yang benar dan akurat, sesuai dengan karakter yang ditentukan dalam bahan hukum normatif dengan menggunakan sistem kerja deduktif dalam bentuk skripsi. Yang dimaksud dengan deduktif adalah menilai dengan menggunakan konsep-konsep yang rasional kemudian barulah ditarik sesuatu kesimpulan.

\section{HASIL DAN PEMBAHASAN}

\section{Kedudukan Wanita Bali yang Daha Tua (Tidak Menikah) terhadap Hak Warisan di Desa Adat Abianbase Kabupaten Gianyar}

Dalam kamus Bahasa Bali daha tua berasal dari kata Daha yang berarti wanita remaja, wanita dewasa; dewasa, akil balig sedangkan Tua berarti sudah tua, (Kaler \& Sugriwa, 1978) Dari beberapa sumber mengenai daha tua penulis berpendapat daha adalah wanita dewasa secara biologis dengan tanda sudah menstruasi, masuk usia belasan tahun hingga batas usia dinyatakan telah tua atau usia lanjut. Setelah wanita pada umur yang dikatakan dewasa saat itulah wanita tersebut dapat diadili secara hukum positif yang ada. Hal yang substandi wanita dikatakan menjadi daha tua karena statusnya yang tidak melaksanakan perkawinan mencapai batas umur untuk kawin dengan adanya tanda berakhirnya kemampuan reproduksi. Jadi daha tua dapat dikatakan seorang wanita yang telah dewasa yang memiliki rentang usia dari 50 tahun hingga telah meninggal dengan status belum pernah menikah atau kawin.

Menurut (Hilman, 2003) sistem pewarisan secara hukum adat dapat dibedakan atas sistem pewarisan individual, sistem pewarisan kolektif, dan sistem pewarisan mayorat, bahwa:

1. Sistem kewarisan individual, yaitu sistem kewarisan yang para ahli waris mewarisi secara perseorangan dan mempunyai sifat dapat dibagi-bagi, seperti harta guna kaya, sawah ladang dan sebagainya. 
2. Sistem kewarisan kolektif, yaitu dimana para ahli waris mewarisi secara kolektif (bersama-sama) dan tidak dapat dibagi-bagi kepemilikannya kepada masing-masing ahli waris, sehingga harus dipelihara dan dimiliki secara bersama.

3. Sistem kewarisan mayorat

1) Mayorat laki-laki, yaitu sistem kewarisan yang bergantung oleh kepemimpinannya anak lakilaki tertua yang bertugas menggantikan menjadi pengganti orang tuanya;

2) Mayorat perempuan, yaitu sistem kewarisan yang diwarisi oleh anak perempuan tertua.

Sesorang yang menjadi daha tua di Abianbase dengan warga yang berada dalam lingkup Desa Adat Abinbase memiliki kedudukan yang sama saja dalam hukum adat di desa adat Abianbase. Kedudukan yang dimaksud yaitu sama-sama harus melaksanakan kewajiban sebagai warga desa dengan mentaati peraturan dan merupakan krama (warga) desa. Namun yang membedakan hanya dalam beberapa ayahan (kewajiban) dalam Desa Adat Abianbase wanita yang menjadi daha tua tidak dikenai ayahan (kewajiban) seperti ngayah jejaritan, gotong royong, mekemit (jaga malam), pesuhan banten (pengeluaran persembahan), membayar cingkreman (urunan) dan ayahan lainnya yang tergolong berat.

Walaupun demikian wanita Bali yang daha tua tetap harus mengikuti jalannya upacara yang ada di Pura. Wanita yang daha tua dapat menjadi perwakilan dalam melaksanakan kewajiban tersebut apabila salah satu dari keluarganya tidak dapat melaksanakan ngayah sangkep ungkap Anak Agung Gde Agung Suardana selaku Bendesa Adat.

Dari awig-awig yang memuat tentang warisan wanita yang daha tua di Abianbase tidak dapat dikatakan sebagai ahli waris. Hal tersebut dikarenakan tidak adanya pengaturan yang tetap tercantum dalam pasal di awig-awig. Dalam wawancara yang dilakukan penulis dengan Anak Agung Gde Agung Suardana selaku Bendesa Adat Abianbase mengatakan bahwa memang wanita yang daha tua di Abianbase tidak ada yang menjadi ahli waris namun tidak adanya larangan bagi orang tua memberikan warisan berupa tanah untuk anak wanitanya yang tentu wewenang sepenuhnya berada di orang tuanya. Hal itu karena beberapa keluarga yang tetap memberikan warisan kepada anak perempuannya.

Wanita yang melangsungkan perkawinan mendapat bekal atau harta bawaan jika dilihat dari sudut pandang hukum hindu, wanita mendapatkan warisan seperempat dari saudara laki-lakinya. Namun jika daha tua ini merupakan anak semata wayang, maka secara langsung menjadi sentana rajeg dalam pengertian merupakan ahli waris satu-satunya karena tidak memiliki saudara. Daha tua dalam kasus seperti ini bisa disebut sebagai purusa, karena sebagai pelanjut tanggung jawab dan kewajiban (swadharna) pada keluarga dan masyarakat. Apabila daha tua berstatus sebagai purusa, maka hak warisnya sejajar dengan laki-laki dan wanita yang berkedudukan sebagai purusa. Hal ini disebabkan oleh karena kewajibannya yang sama dengan laki-laki dan wanita yang berstatus purusa.

\section{Implentasi Hak Waris Wanita Bali yang Daha Tua (Tidak Menikah) di Desa Adat Abianbase Kabupaten Gianyar}

Dalam hasil penelitian yang dilakukan dengan mewawancarai salah satu kerabat dari wanita bali yang daha tua (tidak menikah) Anak Agung Sri Agung Trisna Dewi mengungkapkan bahwa kerabatnya di Puri Ageng Abianbase yang saat ini berstatus daha tua (tidak menikah) mendapatkan warisan peninggalan dari Ajung (Panggilan untuk Bapak/Ayah). Warisan yang didapatnya berupa sebidang tanah seluas $200 \mathrm{~m} 2$, warisan yang diterima merupakan pemberian yang didapat oleh setiap anak perempuan dari ajung (Bapak/ Ayah). Berarti sebagian kecil dari keluarga yang ada di Abianbase sudah memiliki kesadaran dan mengalami perubahan paradigma namun penerapan dalam pengaturannya saja yang belum terlaksanakan. Terlihat dalam beberapa pawos (pasal) yang ada dalam awig-awig hanya menekankan kepada hak warisan kepada ahli waris laki-laki.

Hal ini berarti implementasi hak waris wanita yang daha tua (tidak menikah) setelah adanya Pasamuhan Agung III harus membutuhkan waktu yang cukup lebih lama dan perjuangan yang tidaklah gampang mengingat masih adanya tradisi yang telah mendarah daging dalam masyarakat di Bali termasuk juga di Desa Adat Abianbase, Gianyar. Sehingga dalam pelaksanaanya sekarang terhadap kedudukan wanita Bali yang daha tua masih berpatokan dengan ketentuan yang ada dalam hukum adat dari jaman dahulunya, dimana wanita yang daha tua (tidak menikah) tidak mempunyai kewenangan menjadi ahli waris sehingga wanita yang daha tua tidak memiliki hak untuk mewarisi harta dari orang tuanya. Namun meskipun wanita daha tua tidak memiliki wewenang sebagai ahli 
waris, tetapi beberapa telah menyadari perubahan tersebut dengan adanya pemberian hak warisan kepada wanita. Dimana seorang wanita juga berhak menikmati atas bagian dari warisan yang dimiliki oleh orang tuanya selama wanita tersebut tidak terputus haknya. Putusnya hak untuk menikmati harta warisan itu bisa terjadi apabila wanita Bali yang daha tua itu menikah keluar dan dikeluarkan atau diusir oleh orang tuanya karena suatu hal.

Awig-awig di Desa Adat Abianbase dapat dilihat jika dalam pengaturan mengenai warisan tidak terdapat pawos (pasal) yang mengatur tentang waris wanita daha tua. Jadi dengan adanya putusan MDP harusnya berdampak baik dalam pengaturan hak warisan wanita yang daha tua sebagai wanita yang tetap tinggal di rumah orang tuanya namun dalam implementasi hak warisnya masih kurang kedalam awig-awig desa adat yang menjadi pedoman, menyebabkan kedudukan wanita Bali yang daha tua masih dalam posisi yang sama.

Mengenai jumlah wanita Bali yang daha tua (tidak menikah) di Desa Adat Abianbase berdasarkan hasil telaah penulis dari data Kepada Desa Abianbase. Jumlah ini merupakan jumlah wanita Bali yang daha tua yang diambil dari data Kelihan Adat setempat yaitu Lingkungan Tedung, Lingkungan Kaja Kauh, Lingkungan Kelod Kauh dan Lingkungan Pekandelan. Adapun data jumlah perkiraan adanya daha tua di Desa Adat Abianbase yaitu sebagai berikut:

Tabel 1. Kondisi Wanita Daha Tua Di Desa Adat Abianse

\begin{tabular}{|l|l|l|}
\hline No & Nama Lingkungan & Jumlah \\
\hline 1 & Tedung & 7 \\
\hline 2 & Kaja Kauh & 5 \\
\hline 3 & Kelod Kauh & 3 \\
\hline 4 & $\begin{array}{l}\text { Pekandelan (Br. Adat } \\
\text { Pekandelan, Br. Adat } \\
\text { Semeton Satria) }\end{array}$ & 5 \\
\hline \multicolumn{2}{|l|}{ Total } & 20 \\
\hline
\end{tabular}

Sumber: Peneliti, 2020

Untuk mengetahui secara rinci mengenai kedudukan dan implementasi hak warisan wanita yang daha tua (tidak menikah). Penulis melakukan wawancara untuk mengumpulkan data berupa pendapat dan tanggapan dari seorang daha tua. Dari hasil wawancara terhadap salah seorang dahatua bernama Anak Agung Putri yang berusia 75 tahun membenarkan bahwa beliau tidaklah merupakan salah satu ahli waris dari harta kekayaan orang tuanya. Dalam wawancara beliau menjelaskan walaupum bukan termasuk ahli waris namun ia diberikan sedikit bagian warisan oleh orang tuanya semasih hidup. Warisan tersebut berupa sepetak tanah guna menjadi bekal hidupnya. Disamping itu beliau juga mengatakan memiliki beberapa perhiasan peninggalan ibunya yang diwariskan kepada anak-anak wanitanya. Jadi selain beliau memiliki seorang kakak perempuan juga yang memperoleh warisan yang sama jumlahnya. Hal itu karena sebelum sepeninggal orang tuanya terdahulu membagikan rata harta-harta kepada masing anak wanitanya guna bekal jiwa dana apabila menikah. Namun pada saat ini Anak Agung Putri tidaklah menikah namun yang didapatnya tetap menjadi haknya dan akan diwarisinya kepada yang merawatnya yaitu adalah anak dari kakak laki-lakinya yang menjadi ahli waris. Pemberian kepada keponakannya tersebut karena beliau ikut tinggal dengan keponakannya tersebut yang dianggapnya selayaknya anak kandungnya.

Dari wawancara tersebut berarti dalam keluarga Anak Agung Putri selaku wanita yang berstatus sebagai daha tua berkedudukan sebagai penikmat warisan yang di dapatnya dari peninggalan orang tuanya dan bukanlah seorang ahli waris. Implementasi dari hak warisan wanita sebenarnya telah terdapat sebagian kecil namun dalam pengoohan sebagai peraturan yang paten diterapkan masihlah belum benar-benar berjalan karena sebagian masyarakat Bali masih menerapkan bahwa anak laki-laki yang menjadi purusha yang berhak mendapatkan hak warisan dan menjadi ahli waris.

\section{SIMPULAN DAN SARAN}

\section{Simpulan}

Adapun simpulan yang dapat dikemukakan dalam rumusan masalah tersebut adalah:

1) Kedudukan wanita Bali yang dahatua (tidak menikah) di Desa Adat Abianbase, Gianyar memiliki kedudukan yang sama dalam hukum adat yang ada. Kedudukan yang dimaksud sama-sama harus melaksanakan kewajiban sebagai warga desa dengan mentaati dan 
menjalankan sebagai krama desa yang membedakan hanya dalam ayahan. Dalam awig-awig Desa Adat Abianbase yang membahas warisan jelas tidak disebutkan adanya hak warisan yang diperoleh wanita yang daha tua. Hal ini dikarenakan sepanjang wanita itu tidak kawin, ia tetap diperkenankan untuk menikmati warisan dari kekayaan orang tuanya (guna kaya) sebagai harta kekayaan yang dipakai untuk menjaga kelangsungan hidupnya (jiwa dana). Walaupun tidak memiliki hak untuk mewarisi peninggalan tetapi bagi beberapa pewaris (orang tua yang berada) memberikan dan memberi warisan dengan cara pemberian hibah dan namun apabila daha tua tersebut anak tunggal ataupun tidak memiliki saudara laki-laki maka, maka secara otomatis menjadi sentana rajeg dalam pengertian ahli waris satu-satunya. Daha tua dalam kasus tersebut bisa disebut sebagai purusa, karena merupakan penerus, penanganggung jawab dan swadharma (kewajiban) pada masyarakat dan keluarganya.

2) Implementasi hak waris wanita Bali yang daha tua (tidak menikah) di Desa Adat Abianbase, Gianyar dilihat dari awig-awig setelah terbitnya Keputusan MUDP Bali Tentang Hasil-Hasil Pesamuhan Agung III MDP Bali, pada bagian III bidang Hukum Adat telah diatur kedudukan wanita Bali dalam keluarga dan pewarisan tidak adanya perubahan maka implementasinya harus membutuhkan waktu yang cukup lama dengan sebuah perjuangan yang tidak gampang mengingat menyangkut banyaknya tradisi yang telah mendarah daging dalam bermasyarakat di Bali. Sehingga pelaksanaanya sekarang terhadap kedudukan wanita Bali yang dahatua masih berpatokan pada ketentuan dari hukum adat yang ada dari era lalu yangmana wanita yang daha tua tidak memiliki hak sebagai ahli waris untuk mewarisi harta peninggalan dan menggantikan kewajiban orang tuanya.

\section{Saran}

Saran ditujukan pada para pihak yang terkait, antara lain:

1) Bagi para ahli waris setiap keluarga dalam tatanan masyarakat di Bali khususnya di Desa Adat Abianbase jika penetapan dilakukan dalam awig-awig sebaiknya menerima keputusan yang telah dikeluarkan oleh MUDP agar dirasa keadilannya dalam pembagian warisan dalam sebuah keluarga. Walaupun wanita yang menjadi daha tua tidak berhak menjadi warisan namun berhak menerima warispan setelah dipotong $1 / 3$ untuk harta pusaka dan kepentingan pelestarian sepanjang wanita ini tidak pindah agama dan durhaka pada orang tuanya.

2) Bagi kaum wanita yang daha tua dengan adanya Keputusan Pesamuhan Agung III tersebut, diharapkan agar wanita lebih sadar akan kewajibannya dan tidak hanya menekankan haknya terhadap warisan yang diberikan oleh keluarganya melainkan juga dengan kewajibannya yang harus diterima setelah diterimanya hak waris.

\section{DAFTAR PUSTAKA}

Cahyowati, R. C. (2010). Kedudukan Hak Mewaris Perempuan dari Harta Bersama dalam Hukum Adat Sasak. Perspektif, 15(2), 123-138.

Dangin, N. L. G. I. P., Adi, K., \& Permadi, I. (2015). Kedudukan Hak Mewaris Wanita Hindu dalam Sistem Hukum Adat Waris di Bali [Universitas Brawijaya].

Efendi, J., \& Ibrahim, J. (2018). Metode Penelitian Hukum Normatif dan Empiris. Prenada Media.

Harahap, R. D. K. A. (2013). Kesetaraan Laki-Laki dan Perempuan dalam Hukum Perkawinan Islam. SAWWA, 8(2), 361-386.

Hilman, H. (2003). Pengantar Ilmu Hukum Adat Indonesia. CV. Mandar Maju.

Kaler, I. G., \& Sugriwa, I. G. (1978). Kamus Bali-Indonesia. Dinas Pengajaran Provinsi Daerah Tingkat 1.

Saidah, S. (2017). Kedudukan Perempuan dalam Perkawinan (Analisis UU RI. No. 1 tahun 1974 tentang Posisi Perempuan). Jurnal Al-Maiyyah, 10(2), 292-312.

Septhio, M. R. (2015). Tinjauan Yuridis terhadap Hak Waris Istri dalam Perkawinan Siri pada Masyarakat Adat Aceh di Kecamatan Darul Imarah Mukim Daroy/jeumpet Desa Garot Kabupaten Aceh Besar Provinsi Aceh. Premise Law Journal, 1-18.

Wibawa, M. A. (2006). Wanita Hindu Sebuah Emansipasi Kebablasan. PT. Empat Warna Komunikasi. 